\title{
Doctors crossing borders: Europe's new reality
}

$\mathrm{F}$ reedom of movement is one of the European Union's greatest promises and, increasingly, doctors and patients are making liberal use of that freedom.

In the United Kingdom, for example, the General Medical Council reports that 2205 Polish general practitioners have hung out their shingles since 2000, while the number of German physicians has shot up to more than 8000 from 383 in 2003.

Given that the Council registered 11630 new doctors in 2007, that means about $15 \%$ of all new registrants in the UK since 2003 came from Germany.

And it means that Germany, in turn, has had to pick up more physicians from elsewhere, which it has done by filling posts with doctors from Greece, Austria, Poland and other European nations. In fact, the Bundesärztekammer, Germany's medical association, noted that in 2007, 10069 of the country's 314912 active doctors came from other European Union countries, $8.7 \%$ more than in the preceding year.

In the UK, 74031 foreign doctors were registered to practise in 2007, or $30.94 \%$ of the overall physician pool, with about 20863 coming from other European Union member states. That's a significant shift from the days when the foreign physician ranks were dominated by those from Commonwealth countries.

The problem with this is the strain it creates on states whose doctors typically depart for other countries. Ireland or Malta, for example, report that in 2005 they lost, respectively, $47.5 \%$ (10 065) and 23.1\% (376) of the physicians they had trained.

In short, although the numbers vary from member state to member state, physicians crossing borders has become commonplace within the European Union.

The motivations for all this movement vary. Some doctors are seeking the proverbial "better life" (possibly measured in Euros), relief from hierarchal "father knows best" health care systems or to find situations where private bribes are not a daily staple of practice. A few others are simply on the run, hoping to stay a step ahead of regulatory authorities within their home nations, that have penalized them for some manner of malfeasance.

What are the costs of all this movement? Potentially, patient safety and quality of care.

Arne Björnberg, director of the EuroHealth Consumer Index (a rating organization for health care systems in Europe), says that a general practitioner from Madrid, Spain seeking a taste of northern life in Umea, Sweden faces significant differences in medical practice.

"Whereas in Spain you can get antibiotics for the common cold very frequently, medicine in northern Sweden takes pride in never prescribing antibiotics where there's a virus," Bjornberg says. What constitutes "good medicine" varies widely from nation to nation and even the 6-month monitored adjust- ment periods that some nations have introduced may be less than adequate to fully acquaint physicians with cultural differences in medical practice.

Similarly, an anesthesiologist from Timisoara, Romania, must overcome significant cultural hurdles to practise in Lille, France, even as it becomes easier to enter and register in the country, says Hervé Maisonneuve, president of the Global Alliance for Medical Education and director of continuing medical education for Pfizer Inc.

"Doctors are quite fed up and unhappy at the public hospital levels, and many have moved to private practice. At the public hospital now, which was not the case 10 years ago, if you arrive on the weekend, or you arrive at night, you have a non-French doctor."

In fact, the number of foreigntrained doctors practising in France has attracted considerable media attention, as might be expected given that their ranks swelled by $24 \%$ between 2003

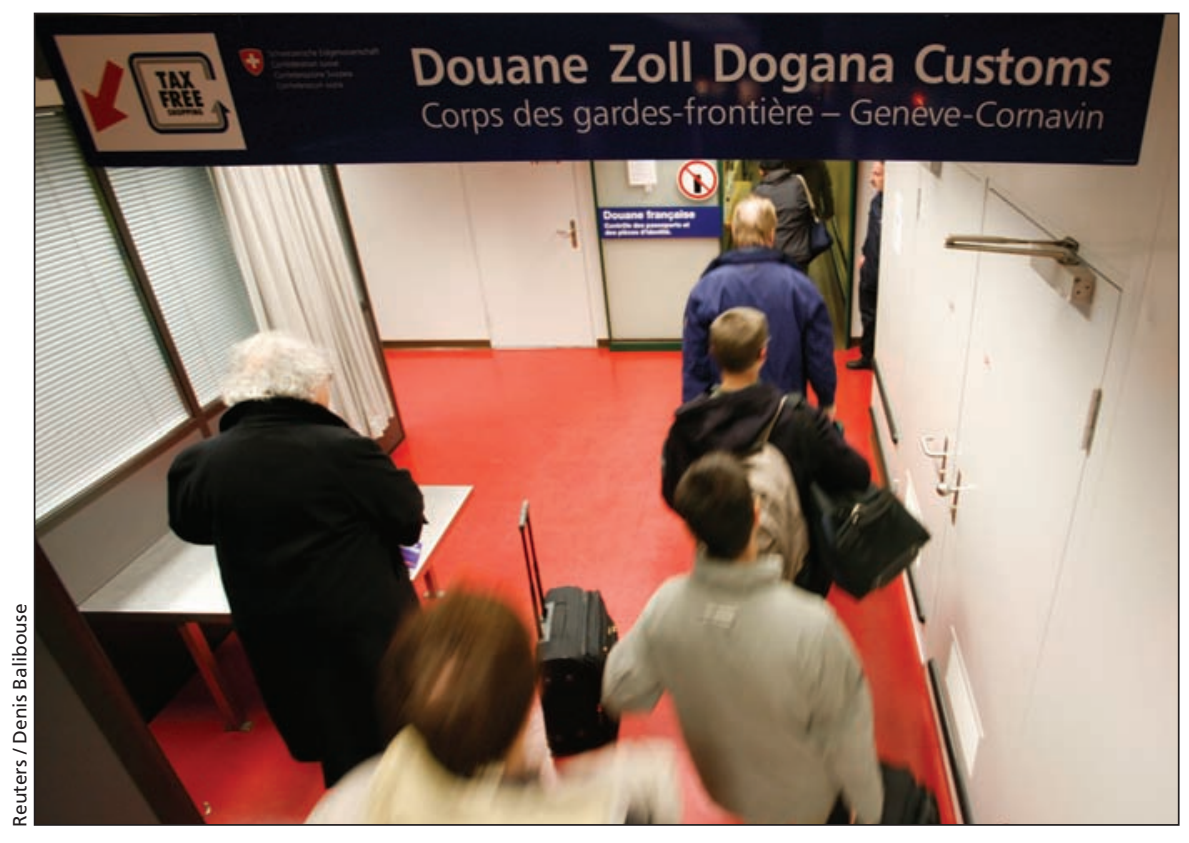

Passengers wait in line at the Swiss border to catch a train for France. Ease of access has become such a norm in Europe that even non-European Union member states such as Switzerland, Norway and Iceland have moved to scrap border controls. Twenty-five nations are now members of the so-called Schengen club of European states, which allow passport-free travel across land borders. 
and 2006. And since the accession of new member states into the European Union in 2004 and 2007, more and more of these physicians are trained elsewhere in Europe. The French l'Ordre National des Médecins reported in 2007, for example, that the number of Romanian doctors registered that year had jumped $321 \%$.

Maisonneuve warns of 3 potential difficulties for non-French doctors practising in France: understanding the health care system, adapting to local practice and language issues. On the latter score, he notes that even doctors from Estonia and Romania, who often speak perfect French, may have trouble understanding subtle cultural cues and thus misunderstand what patients are telling them.

Language and cultural issues aren't always a barrier, as with young Slovakian physicians joining an exodus to the Czech Republic.

One reason for moving is an opportunity to increase their earnings by as much as $20 \%-30 \%$.

As of 2007, there were about 1300 Slovakian doctors working in the Czech Republic, often filling vacancies left by Czech doctor migration to higher-paying jobs elsewhere on the continent.

\section{From east to west}

That has fed what some have called a "medical exodus" from Central and Eastern Europe, with the Czech Republic often becoming a place to practise temporarily while shopping for more lucrative positions in the UK or Belgium. Critics fear there's little reason for such migrant doctors to understand the health care system in which they're practising.

Further fuelling the movement is the fact that many European Union nations now actively recruit doctors from other member states. Sweden, for example, focuses recruitment efforts on Poland, where between 2004 and 2006 more than 5000 doctors received certificates to practise elsewhere $(4.3 \%$ of the active workforce). More than $15 \%$ of the doctors registered in Sweden last year came from outside the country, a situation Björnberg describes as "postcolonial."

In the UK, controversies have erupted over moves by primary care trusts to fly in doctors from around

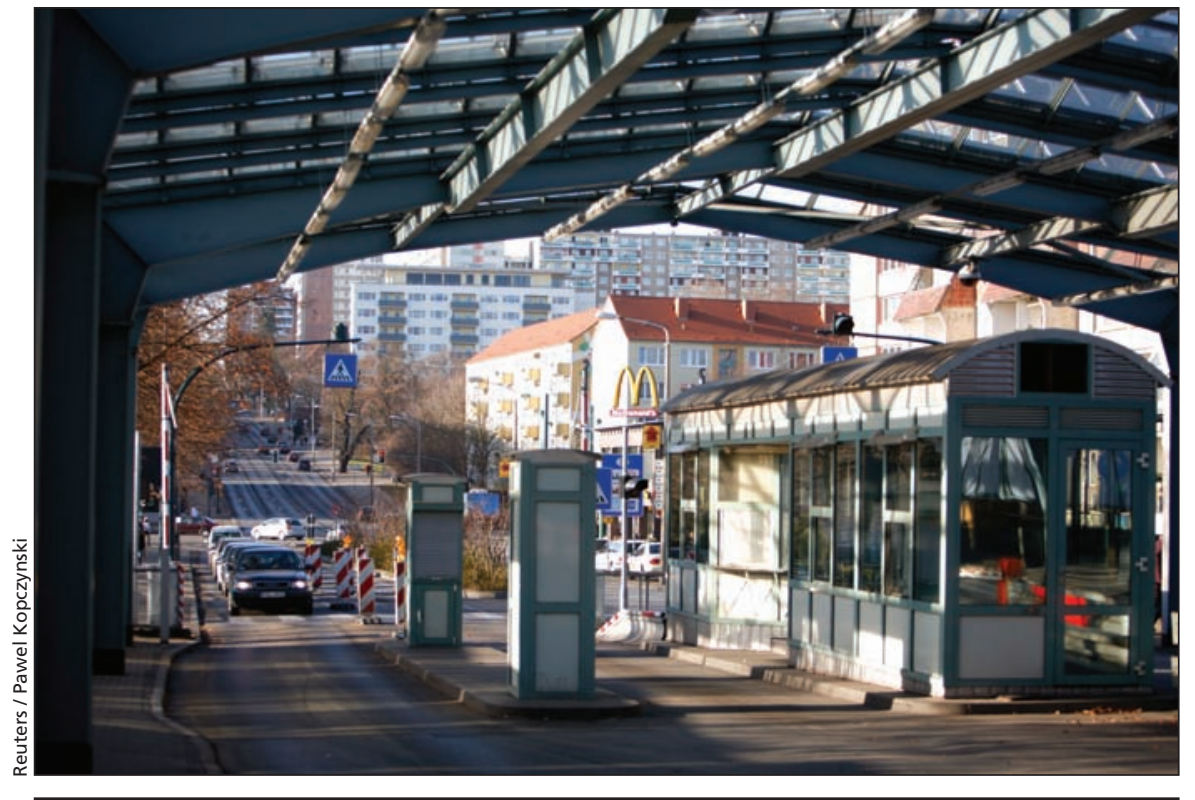

One of the last barriers between the former Soviet Bloc and the West was lifted last year when border checkpoints between Poland and Germany began allowing travel without the need to show passports.

Europe to cover night and weekend shifts, which were unpopular with staff physicians.

Such internal factors, along with an October 2007 European Union directive confirming the rights of professionals to practise outside their home countries, all but assure doctors of ample opportunity to roam the continent.

Not all, though, are pleased, in part because of the potential impact on patient safety.

\section{Patient safety concerns}

"The feedback from patients in Scotland is that they do not want doctors from another country," says Dr. Jean Turner, chief executive officer of the Scottish Patients' Association. "Importing doctors who do not know how our system works, and who, with the best will in the world, may have language difficulties, is fraught with danger."

"Of course, I think it's essential in medicine that you be able to work in different places, but we have Scottish doctors coming through the system and not being able to get jobs, and doctors coming from Eastern European countries to do short-term shift work, often directly after travelling and with too little sleep. It's a matter of meeting not just adequate standards of patient care, but more than adequate standards," she adds.
The latter concern was heightened by a report from the UK General Medical Council stating that 35 foreign-born doctors had lost their licences to practise in 2006, accounting for well over half the 54 doctors struck from physician rolls.

European Union-trained offenders included a Hungarian doctor removed for dishonesty and a psychiatrist trained in Spain who abused his authority to prescribe drugs.

"Doctors with a primary medical qualification from overseas or within the European Union are disproportionately represented [in medical complaints] and more are being referred to us than we should be seeing without a good explanation," said Paul Phillips, director of standards and fitness-to-practise at the General Medical Council, in response to media attention on the disparity.

The British Medical Association, meanwhile, suggested the higher incidence of foreign-born physicians who were delicensed might be the product of a culture of institutional racism within the National Health System. Those arguments were supported by a July 2008 report by the Department of Health's Chief Medical Officer, which concluded that racism was a "cause for concern." In response, the General Medical Council has commissioned several studies on the issue. 
Beyond that lie issues of deceit or misrepresentation by those who have had their licences stripped in one country, but use their new Euro-mobility to set up a shingle in another nation.

A Norwegian doctor who lost his licence for mistreatment of patients, for example, immigrated to Sweden and practised for several years before repeated patient complaints brought his malfeasance to the attention of authorities.

\section{Certification issues}

In theory, such problems are mitigated by European Union directives that mandate countries to share information about the certification of professionals, including doctors. The foremost such directive is 2004/36/EC, which requires exchange of information about fitness to practise and constraints on practice. With an eye to Europe's disparate health care and medical training systems, it further states that "specific provisions should be envisaged for regulated professions having public health or safety implications."

Countries around the European Union have taken a variety of approaches to realize the spirit of this law. In some the response has been broad, in the form of moves to introduce or reintroduce means of continuous revalidation of licences and fitness to practise. In the UK, for example, 150000 doctors will face mandatory annual appraisals in which they'll be assessed on such factors as prescribing habits, diagnostic skills and personal problems, such as alcohol and drug abuse (CMAJ 2008;179[7]:641).

It's hoped the new regulatory regime will also serve as an effective response to problems associated with the increased doctor movement and concerns about how variation in cultural, linguistic and medical competence can affect patient safety.

The UK is also spearheading, on a broader European level, efforts to promote closer regulatory cooperation.

Because the European Union information-sharing is often haphazard, the UK General Medical Council has led a Healthcare Professionals Crossing Borders initiative that offers member states a framework for exchanging licensing data and regulatory best practices.

Dr. Claire Herbert, the project's

\section{Canadian doctors rarely cross provincial borders}

In Canada, most doctors can move with relative ease between provinces and territories. Each province sets it own licensing criteria, which are listed on the websites of provincial colleges of physicians and surgeons, but the major requirements for full licensure are the same.

Mobility will soon be even easier. A national labour mobility deal was struck in December 2008, which will allow regulated professionals to move without restriction within Canada. The CMA, which supports mobility in general, has raised concerns about the new deal, questioning how provinces will manage restricted licences and whether certification standards will suffer.

Presently, few doctors are leaving for other jurisdictions. The Canadian Institute for Health Information says that just 122 crossed provincial or territorial borders in 2007, the lowest figure in 5 years.

To move across borders now, doctors must have medical degrees from accredited Canadian or American universities, or from schools listed in the World Directory of Medical Schools. They must enroll in the Canadian Medical Register and qualify for certification from the College of Family Physicians of Canada or the Royal College of Physicians and Surgeons of Canada.

In general, a Canadian doctor in good standing can practise in any province after supplying the necessary documents and paying the accompanying fees, which include application fees that can cost as little as \$175 (Manitoba) or as much as $\$ 600$ (Ontario). Doctors must also pay the provincial medical authority's annual membership fee, which is usually around $\$ 1200$.

Interprovincial physician mobility was made easier in 1992 when the Federation of Medical Regulatory Authorities of Canada adopted new standards to better align provincial licensing requirements. New requirements included the completion of the Qualifying Examination of the Medical Council of Canada and certification by either the College of Family Physicians of Canada or the Royal College of Physicians and Surgeons of Canada.

In 2001, provincial medical licensing bodies agreed to adhere to these standards but maintained authority to grant temporary, conditional, restricted or other forms of licences depending on special circumstances.

The largest group of physicians practising with restricted licences are international medical graduates, who sometimes must also make service commitments. Foreign-educated doctors who apply for a provisional licence in Saskatchewan, for example, must promise to remain in the same community for at least 3 years. International medical graduates enrolled in Ontario's Registration through Practice Assessment program, which is funded by the Ministry of Health and Long-Term Care, must make 5-year commitments to underserviced communities. - Roger Collier, CMAJ

leader, says "the main focus is developing closer regulatory cooperation around information exchange," at regular interagency meetings. Thus far, sharing data about medical professions in a way that protects patient safety and maintains a physician's privacy has been central to discussions, she adds.

"The relative ease with which an individual can move from one European country to another means that it is necessary that there be appropriate safeguards, so that the small number of individuals who might exploit the situation by moving quickly to avoid disciplinary action cannot do so."

The voluntary association has struggled to achieve consensus, while authoring some unevenly accepted documents, including a May 2008 memorandum of understanding on information-sharing that was signed only by the UK and a small number of medical organizations, including the Cyprus Dental Council, Irish Nursing Board and Norwegian Registration Authority for Health Personnel.

In a shared address to the Healthcare Professionals Crossing Borders initia- 
tive, Catherine Lien Jensen and Lars Swanstrøm, both of the Norwegian Registration Authority, noted that "proactive information sharing between regulators could be fairly uncomplicated in theory, but it seems that differences in systems and culture make the process more complicated and difficult than many may have expected."

Moreover, efforts to promote more regulatory cooperation have been hampered by the refusal of 8 member states - Bulgaria, the Czech Republic, Greece, Latvia, Lithuania, Luxembourg, Romania and Slovakia - to participate.

A study by the World Health Organization, Assuring the Quality of Healthcare in the European Union: A Case for Action, suggests that 6 of the 8 have dodged participation because they "do not have any legislation on quality of care, or national policies on quality." As well, some nonparticipants may be leery of involvement in what is seen as an European Union organ or administrative body.

The Czech Republic and Lithuania have only recently implemented national legislation to control health care quality. The WHO study concludes that, in Lithuania, "the majority of measures envisaged have not been implemented due to lack of funds."

Others argue that many of the problems are associated with the current system for transferring certification between countries.

At present, doctors within the European Union are required to obtain a Certificate of Current Professional Status, which addresses both current status and past training. Complaints arise, the WHO stated, "because the criteria for recognition relate almost exclusively to the length of study, with no consideration of the content."

Despite such concerns, many believe increased mobility helps elevate all systems in the final analysis. As Maissoneuve says, all the movement means "greater competition, which is not absolutely negative, in that it pushes health care systems themselves to adapt and compete." - Ira Allen, Paris, France

DOI:10.1503/cmaj.081817

\section{Colour-coded wristbands confusing}

$\mathrm{T}$ hink of them as a form of hospital shorthand. Commonly used in American hospitals to instantly communicate conditions of patient care, colour-coded hospital wristbands were becoming the norm to signify allergies or do-not-resuscitate orders.

The problem was, in some states, as many as 6 or 7 colours were being used to indicate the same condition, so health care professionals working in multiple settings needed institutional colour charts just to do their jobs.

In a bid to constrain the proliferation American Hospital Association has stepped into the colour fray to simplify and streamline the range of wristband options and thus reduce the likelihood of caregiver error.

The Association has asked all hospitals to pare their list of wristbands to a bare minimum of 3: red for allergy, yellow for fall risk and purple for do not resuscitate.

Standardization of wristband colours has become essential, says American Hospital Association Vice-President Media Alicia Mitchell. "State hospital associations had already taken the lead in trying to standardize these colours. ... It only made sense for us to step in and put together these voluntary guidelines."

The situation was rapidly spiralling out of control, particularly when comand eliminate medical mix-ups, the

bined with fashion trends such as "livestrong" bracelets (yellow silicone wristbands popularized by former Tour de France cycling champion Lance Armstrong to promote cancer awareness), Mitchell adds. It can lead doctors and nurses to make incorrect conclusions about patient needs or preferences and only confuse the situation further.

Some 20 states have already indicated they will adopt the 3-colour guidelines, although many also expanded their colour palate to cover other data, such as white for patient identification or green for patients who are receiving blood products.

Canadian officials say there's no need to move with similar national standards because wristbands are rarely used in Canada as indicators of specific care needs.

"Some facilities may use a red or redstriped wristband to indicate allergies," says Teresa Neuman, communications specialist for the Canadian Healthcare Association. "Other facilities, however, do not [use wristbands] in consideration of patient privacy and confidentiality."

Relevant patient information, such as fall risk or do-not-resuscitate preferences, Neuman adds, is more typically indicated on patient charts in Canada. - Lesley Ananny, Ottawa, Ont.

\section{DOI:10.1503/cmaj.081818}

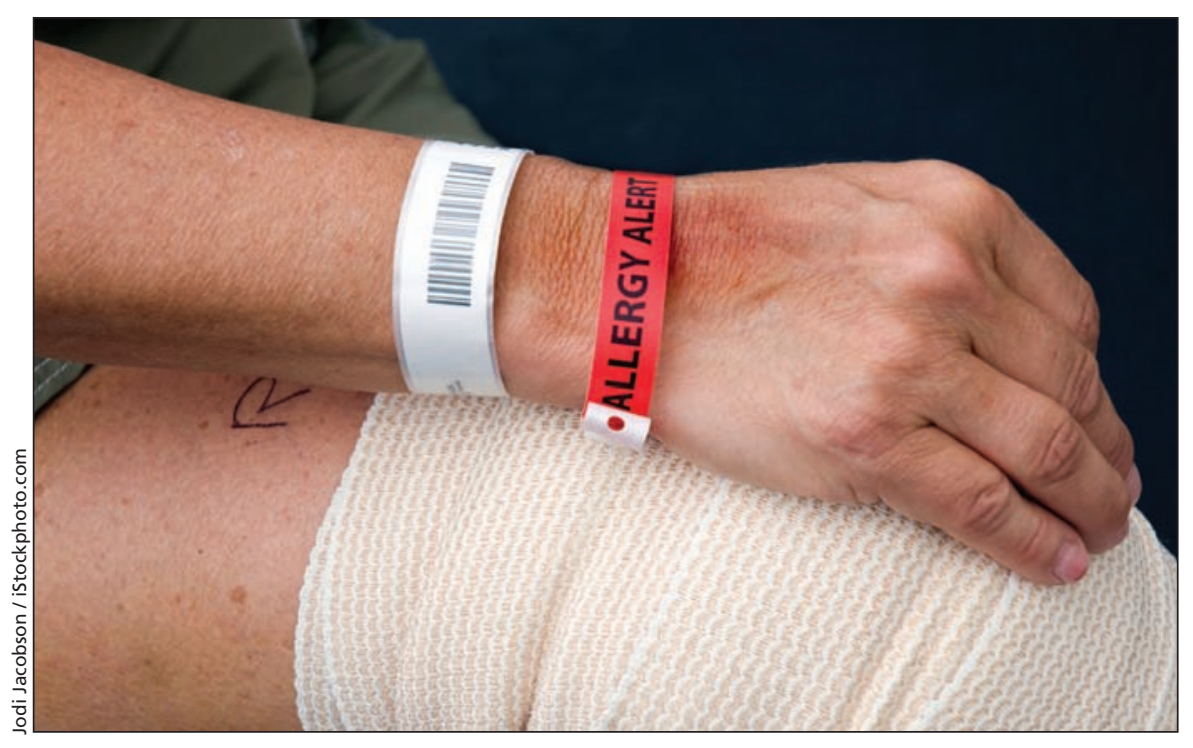

The American Hospital Association is seeking standardization of colour-coded wristbands. 